\title{
Sources of error with cardiovascular PET/CT and PET/MRI and questions to be answered to achieve clinical usefulness
}

Recent articles in Journal of Nuclear Cardiology make a commendable attempt to shed light on some of the variation associated with ${ }^{18} \mathrm{~F}$-FDG PET/MRI and ${ }^{18} \mathrm{~F}$ sodium fluoride PET/CT to elucidate inflammation in the aorta and carotid arteries and coronary microcalcification activity, respectively. ${ }^{1}, 2$ They leave the impression that variations are small and measurements possess a good certainty. However, this is not necessarily the case.

We agree that Bland-Altman analysis and inherent repeatability coefficients assess agreement in absolute terms, but Limits of Agreement (LoAs) are (as is the bias) only estimates, and respective $95 \%$ confidence intervals reflect upon these estimates' uncertainty. Conservatively speaking, it is the lower confidence limit of the lower LoA and the upper confidence limit of the upper LoA (i.e., the outer confidence limits) that deserve interpretation, not only the LoAs as such. Repeated measurements analysis was earlier provided by Olofsen and colleagues, including a respective online tool (https://sec.lumc.nl/method_agreement_analysis). Intra class correlation coefficients provide very limited information as these will by definition always be large as long as there is substantial inter-patient variation. Finally, variance component analysis, based on mixed effects modelling, offers an opportunity to assess repeatability coefficients for the reassessment of (a) the same scan by the same rater, (b) the same scan by a different rater, and (c) a rescan by any rater. ${ }^{4}$

We acknowledge reporting limitations of singlecenter, single PET/MRI or PET/CT system studies. ${ }^{1}{ }^{1}$ However, additional sources of discrepancy include type and make of scanner, tracer dose, time from tracer administration to acquisition, motion correction procedures, among others. All sources must be considered to estimate the certainty of single and repeated measurement in the individual patient. While studies focusing on a few sources of error are highly appreciated, they may create a false impression of measurement certainty that is actually lower than the data seem to suggest.

$$
\begin{array}{r}
\text { Poul F. Høilund-Carlsen, }{ }^{a, b} \text { Oke Gerke }{ }^{a, b} \\
{ }^{a} \text { Department of Nuclear Medicine, Odense University Hospital, } \\
\text { Odense, Denmark } \\
{ }^{b} \text { Department of Clinical Research, University of Southern Denmark, } \\
\text { Odense, Denmark }
\end{array}
$$

\section{Disclosure}

Poul F. Hфilund-Carlsen and Oke Gerke have nothing to disclose.

\section{References}

1. Robson PM, Kaufman A, Pruzan A et al. Scan-rescan measurement repeatability of (18)F-FDG PET/MR imaging of vascular inflammation. J Nucl Cardiol. (2021 May 27). https://doi.org/10.1007/ s12350-021-02627-5

2. Tzolos E, Kwiecinski J, Lassen ML et al. Observer repeatability and interscan reproducibility of $18 \mathrm{~F}$-sodium fluoride coronary microcalcification activity. J Nucl Cardiol. (2020). https://doi.org/10. 1007/s12350-020-02221-1

3. Olofsen E, Dahan A, Borsboom G, Drummond G. Improvements in the application and reporting of advanced Bland-Altman methods of comparison. J Clin Monit Comput 2015;29(1):127-139. https://doi. org/10.1007/s10877-014-9577-3

4. Gerke O, Vilstrup MH, Segtnan EA, Halekoh U, Høilund-Carlsen PF. How to assess intra- and inter-observer agreement with quantitative PET using variance component analysis: a proposal for standardisation. BMC Med Imaging 2016;16(1):54. https://doi. org/10.1186/s12880-016-0159-3

5. Boellaard R, Delgado-Bolton R, Oyen WJ et al. European Association of Nuclear Medicine (EANM). FDG PET/CT: EANM procedure guidelines for tumour imaging: version 2.0. Eur J Nucl Med Mol Imaging 2015;42(2):328-54. https://doi.org/10.1007/ s00259-014-2961-x

doi:10.1007/s12350-021-02750-3

Publisher's Note Springer Nature remains neutral with regard to jurisdictional claims in published maps and institutional affiliations. 